\title{
An Approach for School Counselors: Behavioral Consultation with Parents of Youth with School Attendance Problems
}

\author{
Naoki Maeda ${ }^{1}$, Reiho Inoue ${ }^{2}$ \\ ${ }^{1}$ School of Clinical Psychology, Kyushu University of Health and Welfare, 1714-1, Yoshino, Nobeoka, Miyazaki, \\ 882-8508, Japan \\ ${ }^{2}$ Health Management Center, Kyushu University of Health and Welfare, 1714-1, Yoshino, Nobeoka, Miyazaki, \\ 882-8508, Japan \\ Correspondence: Naoki Maeda, School of Clinical Psychology, Kyushu University of Health and Welfare, 1714-1, \\ Yoshino, Nobeoka, Miyazaki, 882-8508, Japan.
}

Received: July 28, $2021 \quad$ Accepted: September 1, $2021 \quad$ Online Published: September 3, 2021

doi:10.11114/jets.v9i8.5299

URL: https://doi.org/10.11114/jets.v9i8.5299

\begin{abstract}
The current study investigates and discusses the effectiveness of behavioral consultations that school counselors can apply to students with school attendance problems (SAPs). A school counselor adopted the rapid school return approach in a school-based behavioral consultation with parents of a 13-year-old Japanese male student who refused to attend school. After the parents implemented the approach, the student resumed his regular school attendance, which continued until the end of junior high school. The A-B design in a single case study was employed as the research design. Throughout the implementation of the approach, the findings indicated that: (a) school counselors should conduct behavioral consultation sessions with parents periodically; (b) school counselors and parents should discuss who is responsible for the escorting process; (c) school staff and school counselors should collect accurate attendance data of students with SAPs daily until the end of the academic year; and (d) school counselors should view SAPs as a persistent problem for students, which can relapse at certain points during compulsory school. This current case study suggests that behavioral consultation with parents of youth with SAPs can be effective in dealing with students who refuse to attend school and are unwilling to seek specialists' help.
\end{abstract}

Keywords: school attendance problems, school-based behavioral consultation, school counselor, rapid school return approach

\section{Introduction}

Numerous scholars have discussed school attendance problems (SAPs) as a universal psychosocial issue for a long time (Maeda \& Hatada, 2019); and despite the breadth of studies conducted in this field to date (Maeda, 2017), the number of youth with SAPs has been increasing globally (Gren-Landell, 2021). Currently, 17.8\% of youth do not attend school, $4.3 \%$ of whom are from Europe and North America (Kearney, Gonzalvez, Graczyk, \& Fornander, 2019a). School is a crucial environment for youth development (Heyne, Gren-Landell, Melvin, \& Gentle-Genitty, 2019) as it enables them to acquire academic, social, communication, and problem-solving skills, as well as stress tolerance and other abilities. Once students are isolated from the school environment due to SAPs, they experience difficulties in acquiring these skills and abilities. Moreover, SAPs lead to significant consequences, such as academic underachievement, family difficulties, deteriorating peer relationships, employment difficulties, and increased risk of psychiatric illness (Fremont, 2003; Sewell, 2008). Scholars have highlighted that if conditions surrounding SAPs are prolonged, then addressing the problem would become increasingly challenging (King et al., 1998; Okuyama, Okada, Kuribayashi, \& Kaneko, 1999; Sonoda, Hashimoto, Ishibashi, \& Kamohara, 2008; Terada, 2010; Thambirajah, Grandison, \& De-Hayes, 2008). Moreover, the perpetuation of SAPs would increase young peoples' anxiety about returning to school return (Thambirajah et al., 2008; Terada, 2015) and likely reduce their motivation to resolve their aversion to attending school. Recent studies have also emphasized the importance of early identification of and intervention for SAPs upon their onset (e.g., Brouwer-Borghuis, Heyne, \& Sauter, 2019; Heyne, 2019; Ingul, Havik, \& Heyne, 2019; Kearney \& Graczyk, 2014). Of several approaches to address SAPs, cognitive behavioral therapy (CBT) and behavioral 
intervention are commonly utilized (Heyne, Strombeck, Alanko, Bergstrom, \& Ulriksen, 2020), and the importance of close cooperation between parents and school staff is widely recognized (Elliott \& Place, 2019).

\section{SAPs in Japan}

In Japan, SAPs are defined as a student's absence from or inability to attend school for more than 30 days per year due to physical, psychological, social, and/or emotional factors except for medical and economic reasons (Ministry of Education, Culture, Sports, Science, and Technology-Japan [MEXT], 2003). Simply put, each school for compulsory education is responsible for checking the school attendance data of all students every day and issuing regular reports of these statistics to the local board of education. According to Ministry of Education, Culture, Sports, Science, and Technology-Japan (MEXT) (2019), the number of students with SAPs in the country has reached 44,841 (0.7\%) in elementary school and 119,687 (3.7\%) in junior high school, the highest since the government implemented the current data collection format in 1991. A national survey conducted by MEXT (2019) identified student apathy (family factor) was the leading cause of SAPs, followed by trouble with friends (school factor) and student anxiety (family factor), in schools for compulsory education. These results indicated that a considerable number of SAPs among Japanese students in recent years are significantly associated with parental factors. Against this background, SAPs based on parental attitudes and the home environment have been notable in the Japanese context in the past few years (e.g., Ishikawa, 2002; Maeda \& Hatada, 2019; Maeda \& Heyne, 2019).

Heyne et al (2019) classified SAPs into four types—-school refusal (SR), truancy (TR), school withdrawal (SW), and school exclusion (SE) - through their School Nonattendance ChecKlist (SNACK), which was the first comprehensive classification tool for screening SAPs. Maeda and Hatada (2019) used the SNACK to examine 35 students with SAPs at a junior high school in Japan and found that $74.3 \%(\mathrm{n}=26)$ experienced $\mathrm{SW}$, which is associated with family factors. Moreover, more than $90 \%$ of them did not utilize any specialist support, suggesting that Japanese students with SAPs are less likely to call on specialists for help. However, because this study was a pilot case study on the SNACK in Japan, the authors refrained from concluding that SW reflects the common features of SAPs among Japanese students. The results suggested that providing appropriate measures not only for students but also for their parents is imperative due to the increase in parent-driven SAPs.

\section{SAPs and School Counselors in Japan}

With the increasing number of students with SAPs and bullying issues during the 1990s, MEXT implemented the school counselor project (MEXT, 2007) and assigned school counselors to 122 public compulsory schools (elementary and junior high) nationwide in 1995 (MEXT, 2015). Since then, the number of schools with designated school counselors has dramatically increased; by 2018, school counselors have been assigned to a total of 23,164 public compulsory schools (out of 27,500) (MEXT, 2020). The majority of these school counselors were part-time workers employed by local boards of education, and $80 \%$ of them were licensed clinical psychologists certified by the Foundation of the Japanese Certification Board for Clinical Psychologists (MEXT, 2007). Besides working as school counselors, most of them were employed as licensed clinical psychologists in other special institutions such as hospitals, welfare organizations, and universities.

Addressing students' SAPs has been the most important task for school counselors in line with the main goal of the school counselor project (MEXT, 2007). As previously mentioned, however, the number of students with SAPs has significantly increased, whereas that of designated school counselors has seen a dramatic increase since the implementation of the project. A possible reason for this is that school counselors lack appropriate evidence-based measures (e.g., CBT or other behavioral approaches) to deal with SAPs. Many school counselors have adopted the individual therapy model, showing a lack of school-level training before working in schools (Yagi, 2008). When supporting students with SAPs at the school level, school counselors frequently confront their inability to undertake individual counseling sessions, as students with SAPs are reluctant to come to the counseling office at school (Maeda, Hatada, Sonoda, \& Takayama, 2012). Under such circumstances, only parents (mainly mothers) or school staff visit school counselors, who may then inevitably discuss specific school-based approaches without interviewing students and directly evaluating them (Maeda \& Heyne, 2019). In other words, school counselors should acquire specific knowledge and techniques for SAPs under the assumption that they cannot hold individual counseling sessions with students suffering with SAPs.

Several case studies have demonstrated the effectiveness of school-based behavioral approaches for SAPs provided by school counselors on students who refuse individual counseling sessions (e.g., Maeda \& Heyne, 2019; Maeda, 2016; Maeda et al., 2012; Maeda, Takayama, \& Sonoda, 2012). In these approaches, conducting behavioral consultations with parents and the school staff is crucial for addressing SAPs. School counselors provide basic behavioral theory, outline the formation process of SAPs, highlight the negative effects of long-lasting SAPs (e.g., academic underachievement, employment difficulties, and increased risk of psychiatric illness), and propose behavioral management strategies that 
aim to improve school attendance (e.g., the process of flooding and coping skills for addressing resistive behaviors; Maeda, 2016; Maeda et al., 2012). In accordance with these consultations, Maeda and Heyne (2019) implemented the rapid school return approach, which is school-based, to 39 cases of SAPs (SR type) in Japan and reported that 28 cases (72\%) resumed their normal school attendance at their original schools. However, because this study was an uncontrolled case series, further research requires case studies to evaluate the success of this type of school-based approach (Maeda \& Heyne, 2019).

Therefore, the current study presents the case of one student with SAP (SR type) who was unwilling to call on specialists for help and whose parents asked for help from the school counselor. In response, the school counselor held school-based behavioral consultations with the parents. This study explores the effectiveness of these sessions and discusses a practical approach to solving students' SAPs that school counselors can utilize.

\section{Method}

\subsection{Participants}

The participants were the parents of a 13-year-old Japanese male student who met the following rapid school return approach criteria for SR youth (Maeda \& Heyne, 2019): (a) fulfillment of Berg's (1997, 2002) SR criteria; (b) refusal to undergo individual sessions; (c) undiagnosed with physical and mental disorders; (d) lack of bullying or interpersonal problems; (e) immersion in TV, video games, the Internet, or comic books; and (f) lack of support from specialists.

\subsection{Research Design}

The current study adopted the A-B design in a single case study. The baseline period was four weeks, and the intervention period was 71 weeks. Data on class attendance rate was used as an outcome measure.

\subsection{Data Analysis}

Class attendance rates were compared between the baseline and intervention periods. With regard to effect size, the present study employed the percentage of non-overlapping data (PND) in accordance with Takahashi and Yamada's criteria (2008) as follows: 32.98 (small effect), 83.77 (medium effect), and 100 (large effect) using a non-regression approach.

\subsection{Case Presentation}

Student B was a 13-year-old Japanese male student (seventh grade) enrolled in a local public junior high school. His family consisted of his father, mother, and two elder sisters. His father was a construction worker, whereas his mother was unemployed. He was an introverted with a slightly below-average academic performance. He also had many friends from early childhood and had not exhibited any interpersonal problems. In elementary school (first to sixth grade), Student B frequently missed school due to abdominal pain and diarrhea. In the first two months of seventh grade (in Japan, the school year begins in April), he had a perfect school attendance, but he would miss school on days with a semester test (June 25 and 26, 2018), complaining of abdominal pain. A medical examination confirmed that he was free of any physical or mental disorder; in fact, his somatic symptoms would disappear after his parents decided that he would not attend school. Since the semester test, Student B intermittently refused to attend school due to somatic complaints, which led to an increase in tardiness and absenteeism. The classroom teacher conducted a home visit after Student B was absent for three days within the previous 20 days. However, the mother was uncomfortable with this, as earlier during the day she had phoned a school official about Student B's absence due to somatic symptoms. After this event, the mother became unwilling to consult with the classroom teacher about Student B's SAP and approached the school counselor (the first author, NM) for a consultation.

\subsection{Interview Session With the Mother}

On July 19, 2018, the school counselor interviewed the mother, who reported the following. (a) Although Student B was willing to attend school, he was unable to do so due to stomachache and diarrhea at the time of leaving for school in the morning. (b) When the mother decided that he should stay home, his symptoms would disappear at approximately 11:00 a.m. Afterward, he would stay home with on somatic complaints. (c) While at home, he would play games on his smartphone or watch TV all day. Lastly, (d) he was unwilling to receive help from specialists. Based on the information provided by the mother, the school counselor arranged a consultation session with Student B' parents during the five-week summer holidays.

\subsection{Consultation Session With the Parents}

On August 22, 2018, the parents and school counselor held a consultation session regarding Student B and his SAP. The behavioral analysis results, based on the information provided by the parents, indicated that Student B refused to attend school due to somatic complaints, which were derived from test anxiety. At the same time, tangible reinforcers, such as free access to the TV and smartphone (online games), encouraged his school avoidance behavior. Since then, Student B 
did not attend school due to somatic complaints in the morning, which reinforced and maintained his school nonattendance behavior. The counselor classified Student B's SAP as SR. In addition, the parents' report of their son's situation met the criteria for the rapid school return approach for SR youth (Maeda \& Heyne, 2019).

Subsequently, the school counselor explained the process of rapid school return approach for SR: the parents were to (a) clearly explain to Student B the flooding-based approach before starting implementation; (b) set a wake-up time, facilitate preparation including changing into his school uniform, and escort him to school by car; and (c) purposely ignore his SR-related behaviors, such as crying, somatic complaints, or temper tantrums (Maeda \& Heyne, 2019). Only the parents conducted the intervention after refusing to involve concerned parties such as the school counselor or school staff.

\section{Results}

Week 1 (August 27-31, 2018)

The intervention immediately began after the summer holiday. Student B attended school without any support from his parents on the first and second days. However, on the third day, he refused to put on his school uniform and attend school, so his parents escorted him to school as agreed in the consultation. Student B displayed serious resistive behaviors while being escorted by his parents; therefore, the father escorted him physically and followed the planned disregard of his resistive behaviors. At school, Student B was escorted to the school's nursing office in the middle of the second class, where his parents and school staff urged him to change into his school uniform. Before the third class, a close friend of Student B fetched him from the nursing office and escorted him to the classroom. At this point, Student B showed no resistive behaviors and attended four out of six classes without complaining about any physical and emotional distress. This behavioral pattern continued for three days (days 3 to 5 ).

Week 2 (September 3-9, 2018)

Although the parents escorted Student B to school for four days (Monday, Tuesday, Wednesday, and Friday), he displayed improvement in his resistive behaviors compared with the first week. On Tuesday, Students B attended school without complaints. He arrived at school in the middle of the second class on Monday, Wednesday, and Friday. Although Student B visited the school's nursing office immediately after arriving to school and went to the classroom escorted by his close friend only on Monday, from Tuesday onward he went to the classroom without visiting the nursing office.

\section{Weeks 3 to 5 (September 10-28, 2018)}

By the third week, Student B attended school normally for five days without parental support. He went to school with his friends on Monday, Thursday, and Friday and by himself on Tuesday and Wednesday. In the fourth week, Student B attended school for four days without complaints (Monday, Tuesday, Wednesday, and Friday). On Thursday, however, he felt reluctant to go to school, such that the parents escorted him to school, where he attended four classes out of six without any problem. On Tuesday of the fifth week, his parents escorted him to school in the middle of the second class, as he refused to go. Student B took the rest of the class without displaying any signs of distress. For the remainder of that week, he went to school without help and attended all his classes as per usual.

\section{Weeks 6 to 18 (October 1, 2018-January 11, 2019)}

From the sixth to the 18th week, Student B went to school without support and attended all his classes on time. Although the 18th week was the first week after a two-week winter holiday, he attended all classes without complaints about any distress.

\section{Weeks 19 to 20 (January 15-25, 2019)}

On the 19th week, Students B contracted influenza and was therefore officially allowed not to attend school for three days (Tuesday, Wednesday, and Thursday). On Friday, the day he legitimately had to return to school, Student B refused to go and exhibited serious resistive behaviors, which made the parents spend more time to escort him to school. Student B arrived at school in the middle of the third class and attended the rest of the classes (three out of six). On Monday of the 20th week, the parents escorted Student B to school due to serious resistive behaviors in the morning. He stayed for a few hours in the school counseling office, refused to go to class, and left the school early. In the next two days, Student B locked himself in the bathroom and stayed there for hours before the parents escorted him. This event resulted in a two-day absence from school. On Thursday, Student B then returned to school escorted by his parents and attended all his classes. His school attendance returned to normal on the following day. 
Student B's school attendance stabilized since resuming his regular school attendance on the last day of the 20th week. $\mathrm{He}$ also attended his classes full-time for eight weeks until the end of seventh grade. During this period, Student B did not display SR behaviors and somatic complaints. Thus, his parents were not required to escort him to school. However, the school counselor arranged for a consultation with the parents at school because the school counselor and school staff were concerned about the recurrence of SR behaviors after the spring holiday (March 25-April 4, 2019). During the consultation, the parents were encouraged to prepare to escort their son whenever he refused to go to school for certain reasons.

\section{Weeks 31 to 71 (April 5, 2019-March 1, 2020)}

After the spring holiday, Student B was moved up to eighth grade, where his school attendance remained stable without support. He was absence for three days (out of 190 school days) due to sickness (cold and fever) within this period. After the absence, he returned to school without any problem or support. Except for these three absences, Student B achieved full-time school attendance (187 days: 98\%) without tardiness. In April 2020, however, the school counselor in charge of the case was then transferred to another junior high. Thus, the school staff reported to the counselor that Student B had moved up to ninth grade in April 2020 and achieved 100\% of school attendance until the end of junior high school in March 2021 (191 school days).

\section{Effect size}

The current study calculated the PND until week 35 in accordance with Takahashi and Yamada's criteria (2008), which reached 88.57 and indicated a medium effect.

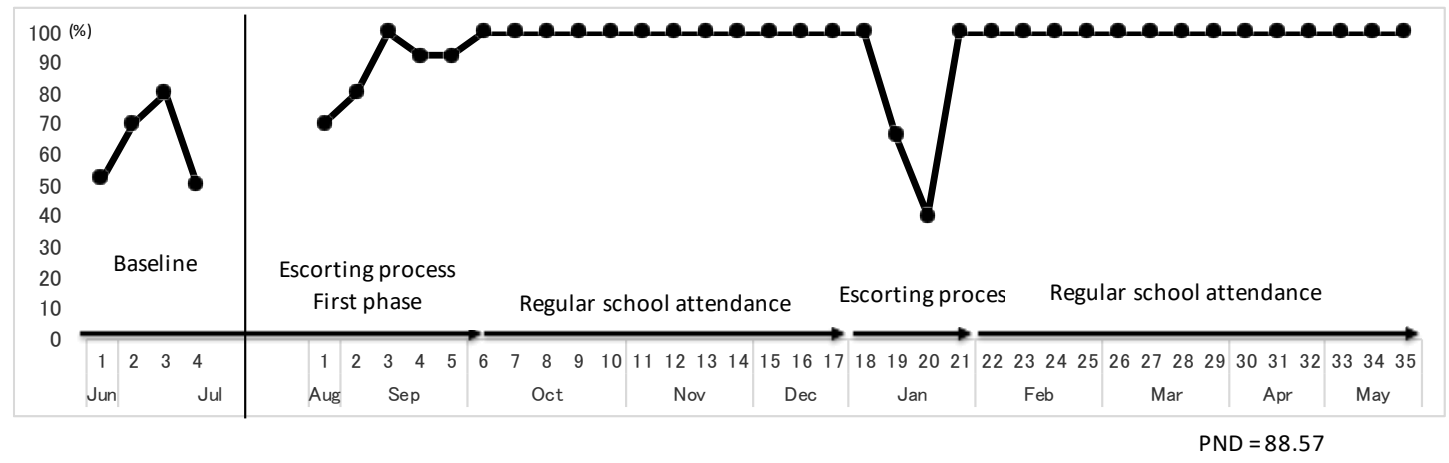

Figure 1. Student B's class attendance rate

Table 1. Escorting process (Phase 1)

\begin{tabular}{|c|c|c|c|c|c|c|c|}
\hline Week & Date & Day & Intervention day & Escort & Resistive behavior & Arrival time & Rate of class attendance (\%) \\
\hline \multirow{5}{*}{1} & $8 / 27$ & mon & 1 & None & None & On time & 100 \\
\hline & $8 / 28$ & tue & 2 & None & None & On time & 100 \\
\hline & $8 / 29$ & wed & 3 & Parents & High & Second class & 50 \\
\hline & $8 / 30$ & thu & 4 & Parents & High & Second class & 50 \\
\hline & $8 / 31$ & fri & 5 & Parents & High & Second class & 50 \\
\hline \multirow{5}{*}{2} & $9 / 3$ & mon & 6 & Parents & Middle & Second class & 66 \\
\hline & 9/4 & tue & 7 & Parents & Middle & First class & 100 \\
\hline & $9 / 5$ & wed & 8 & Parents & Middle & Second class & 66 \\
\hline & 9/6 & thu & 9 & None & None & On time & 100 \\
\hline & 9/7 & fri & 10 & Parents & Middle & Second class & 66 \\
\hline \multirow{5}{*}{3} & $9 / 10$ & mon & 11 & Friend & None & On time & 100 \\
\hline & 9/11 & tue & 12 & None & None & On time & 100 \\
\hline & 9/12 & wed & 13 & None & None & On time & 100 \\
\hline & 9/13 & thu & 14 & Friend & None & On time & 100 \\
\hline & $9 / 14$ & fri & 15 & None & None & On time & 100 \\
\hline \multirow{4}{*}{4} & $9 / 18$ & tue & 16 & None & None & On time & 100 \\
\hline & 9/19 & wed & 17 & None & None & On time & 100 \\
\hline & $9 / 20$ & thu & 18 & Parents & Middle & Second class & 66 \\
\hline & $9 / 21$ & fri & 19 & None & None & On time & 100 \\
\hline \multirow{4}{*}{5} & $9 / 25$ & tue & 20 & Parents & Middle & Second class & 66 \\
\hline & $9 / 26$ & wed & 21 & None & None & On time & 100 \\
\hline & $9 / 27$ & thu & 22 & None & None & On time & 100 \\
\hline & $9 / 28$ & fri & 23 & None & None & On time & 100 \\
\hline
\end{tabular}


Table 2. Escorting process (Phase 2)

\begin{tabular}{|c|c|c|c|c|c|c|c|}
\hline Week & Date & Day & Intervention day & Escort & Resistive behavior & Arrival time & Rate of class attendance (\%) \\
\hline \multirow{5}{*}{19} & $1 / 15$ & tue & \\
\hline & $1 / 16$ & wed & \multicolumn{5}{|c|}{ Absence due to flu } \\
\hline & & & & & & & \\
\hline & $1 / 18$ & fri & 91 & Parents & High & Third class & 50 \\
\hline & $1 / 19$ & sat & 92 & Parents & Middle & Second class & 66 \\
\hline \multirow{4}{*}{20} & $1 / 21$ & mon & 93 & Parents & High & Third class & 0 \\
\hline & $1 / 22$ & tue & 94 & Parents & High & Failed to escort & 0 \\
\hline & $1 / 23$ & wed & 95 & Parents & High & Failed to escort & 0 \\
\hline & $1 / 24$ & thu & 96 & Parents & Middle & On time & 100 \\
\hline
\end{tabular}

\section{Discussion}

The case presented here of the student with SAP is relatively typical for school counselors assigned to public schools for compulsory education in Japan. Student B's mother visited the school counselor after a medical examination cleared him of physical and psychological disorders. During the first consultation session with the mother, confirming the parents' attitudes toward school and their relationship with school staff was an important step for the school counselor. In this regard, relevant studies emphasized that cooperation between the school staff and parents of students with SAPs facilitated the solution to the problem (e.g., Heyne \& Rollings, 2002; Kearney \& Bates, 2005; Kearney \& Bensaheb, 2006; Richardson, 2016).

Classroom teachers in Japan are usually encouraged to organize home visits when students do not attend school within a certain period (Maeda \& Hatada, 2019). In many cases, the timing of such visits depends on classroom teachers or the school. In the present case, the classroom teacher decided to conduct a home visit when the number of Student B's illegitimate absences reached three days within the previous 20 days (15\%), which is considered a relatively prompt response. However, Student B's mother was unsatisfied with the early home visit from the classroom teacher because she had informed the school of her son's inability to attend school due to somatic complaints at the time. In response, the school counselor explained the situation of the schoolteacher to the mother. Furthermore, the school counselor asked for her understanding regarding the event to avoid worsening the relationship between the mother and the classroom teacher. To prevent this situation, each school or classroom teacher should develop a procedure description of home visits to students who miss a specific number of school days or classes and convey such intent to all parents through a polite letter before a new semester starts.

The mother requested a consultation with the school counselor before the five-week summer holidays, where Student B was absent for seven days out of the last 20 school days $(35 \%)$. In the consultation session with the parents during the summer holidays, the school counselor suggested that the parents implement the rapid school return approach in accordance with Maeda and Heyne's (2019) criteria. The parents acknowledged their accountability and agreed to adopt the approach, which was a critical confirmation because it enabled the school counselor to address the present case. The parents could have otherwise opted not to impose to their child a return to school given the present compulsory education system in Japan, which issues automatic promotions and diplomas to all enrolled students regardless of school attendance record and individual academic achievement (Maeda \& Hatada, 2019). In addition, if parents fail to urge their children to attend school, school authorities or local education boards impose virtually no legal sanctions (Shinohara, 2008), which frequently discourages parents from convincing their school-refusing children to attend school. School counselors who need to address SAPs in Japan should be aware that once parents opt not to impose school attendance on their children with SAPs, finding solutions to the problem against the background of the current Japanese school system will be a great challenge.

During the intervention process, Student B attended school on the first and second days after the summer holidays without support from his parents. This tendency frequently emerges during the implementation of the rapid school return approach, in which many students with SAPs attend school only during special events, such as school excursions, graduation ceremonies, or school festivals, which are thought to alleviate their distress about attending school. On the first two days of the new semester, Students B's school did not provide regular academic classes, which may have relieved his distress regarding school attendance. However, on the third day, when Student B started refusing to attend school, the parents implemented the escorting process as the first phase of the intervention. This phase continued for five weeks (23 days), out of which the parents escorted Student B to school nine days (39\%). Out of these nine days, seven were within the first two weeks. In the flooding process, many of the physical and psychological burdens experienced by the parents of the child with SAPs occur during the first week (Maeda, 2016). The current case followed 
this process, where Student B displayed serious resistive behaviors during the first week, which then improved by the second week.

Student B's school attendance remained stable between the sixth and 18th weeks, during which he attended all his classes. However, his SR relapsed on the 19th week, and his parents reimplemented the escorting process, which is considered the second phase. Compared with the first phase, Student B's resistive behaviors were more serious in the second phase, and the parents failed to escort him to school on two occasions. Before the relapse, he was officially absent for three days due to his flu, which was his longest consecutive school absence since the intervention was implemented. This event may have intensified his distress in returning to school, which encouraged his serious resistive behaviors. In this phase, the parents continued the escorting process in accordance with the intervention plan for six days, which caused Student B's school attendance to normalize. After the escorting process in the second phase (20th week), Student B continued to attend school full-time until the school counselor was transferred to another school by the 71st week. Afterward, he continued his full-time school attendance until the end of junior high school (191 days).

The present case study reveals that as long as students with SAPs are enrolled in compulsory schools, school counselors would experience difficulty in terminating the intervention. The reason underlying this notion is that even when students with SAPs resume their regular school attendance, the problem may relapse at some points during the compulsory education period. In fact, MEXT (2009) stated that all students could suffer from SAPs for certain reasons, which is not the case for specific students with personal problems. Therefore, school counselors should provide parents with information about relapses among students with SAPs and encourage them to escort their children whenever they show reluctance toward attending school. In other words, SAPs should be viewed as a continuing problem that may happen to young students during the compulsory education period. The authors' clinical impression is that if the parents and school staff regularly prepare for the escorting process in case of relapse and implement it whenever students show resistance against attending school, the interval between relapses will be larger, and students' distress toward school will be alleviated. Therefore, school counselors, especially those assigned to schools for compulsory education, should follow-up and support students with SAPs until the end of their assignment or even after these students resume a regular school attendance within a certain period of time.

With the rapid increase in Japanese youth with SAPs, many consultation or educational services aiming to provide educational or psychological support for this group of students and their parents have been developed in the past decade. However, Japanese students with SAPs have rarely used such services proactively. In other words, practitioners, such as school counselors must understand the fact that they may be frequently unable to provide support for students with SAPs based on the assumption that these students may use such services with high levels of motivation to solve the problem.

Several support services, such as child-care centers, child psychiatry clinics, or school counseling offices, frequently require parents to encourage their children with SAPs to attend individual sessions. However, parents may be unable to physically bring their children into these services due to rejective or resistive behaviors. In such cases, family members (mainly parents) are left with no choice but to address the problem by themselves because these support services typically do not help them escort students to special institutions. Therefore, practitioners tasked to address SAPs should consider individuals assigned to bring students with SAPs who refuse help to centers for support services and prepare an intervention strategy with the assumption that these students are unwilling to solve their problems. The current case study provides several ideas for addressing a typical case of SAP in Japan, which may be more common in other countries.

\section{Conclusion}

The current case study suggests that behavioral consultation with parents of youth with SAPs can be effective for dealing with school-refusing students who are unwilling to utilize specialist services. In summary: (a) school counselors should conduct behavioral consultation sessions with parents as soon as possible; (b) the school counselor and parents should discuss who will take responsibility for the escorting process; (c) the school staff and school counselor should collect accurate school attendance data of a student with SAPs daily until the end of their assignment to the school; and (d) school counselors should view SAPs as a continuing problem for students that can relapse at several points during the compulsory education period.

The current study has its limitations. Frist, no direct assessment was undertaken with Student B because he was essentially unwilling to receive any help from the school counselor. Thus, his mental health status or severity of SR during the intervention remained unknown; hence, only his school attendance data was used as a criterion to evaluate the effectiveness of the intervention. Second, this study was an uncontrolled case study, which provides limited results. Although it employed PND to evaluate the effectiveness of the approach with more evidence compared with those of other single case studies in this field, future research efforts must conduct controlled case studies using the same criterion to support the results of the current study. 


\section{References}

Berg, I. (1997). School refusal and truancy. Archives of Disease in Childhood, 76, 90-91. https://doi.org/10.1136/adc.76.2.90

Berg, I. (2002). School avoidance, school phobia, and truancy. In M. Lewis (Ed.), Child and Adolescent Psychiatry: A Comprehensive Textbook (pp. 1260-1266). Sydney: Lippincott Williams \& Wilkins.

Brouwer-Borghuis, M., Heyne, D., Sauter, F. M., \& Scholte, R. H. J. (2019). An alternative education program in the Netherlands to reengage school-refusing adolescents with schooling. Cognitive and Behavioral Practice, 26, 75-91. https://doi.org/10.1016/j.cbpra.2018.08.001

Elliot, J. G., \& Place, M. (2019). Practitioner review: School refusal: developments in conceptualization and treatment since 2000. Journal of Child Psychology and Psychiatry, 60, 4-15. https://doi.org/10.1111/jcpp.12848

Fremont, W. P. (2003). School refusal in children and adolescents. American Family Physician, 68, 1555-1561.

Gren-Landell, M. (2021). Introduction. In M. Gren-Ladell (Ed.), School Attendance Problems: A Research Update and Where to Go (pp. 19-38). Stockholm: Jerring Foundation.

Heyne, D. (2019). Development in classification, Identification, and intervention for school refusal and other attendance problems: Introduction to the special series. Cognitive and Behavioral Practice, 26, 1-7. https://doi.org/10.1016/j.cbpra.2018.12.003

Heyne, D., \& Rollings, S. (2002). School Refusal, Parents, Adolescent and Child Training Skills 2, BPS Blackwell.

Heyne, D., Gren-Landell, M., Melvin, G., \& Gentle-Genitty, C. (2019). Differentiation between school attendance problems: Why and how? Cognitive Behavioral Practice, 26, 8-34. https://doi.org: 10.1016/j.cbpra.2018.03.006

Heyne, D., Strombeck, J., Alanko, K., Bergstrom, M., \& Ulriksen, R. (2020). A scoping review of constructs measured following intervention for school refusal: Are we measuring up? Frontiers in Psychology, 11, 1744. https://doi.org/10.3389/fpsyg.2020.01744

Ingul, J. M., Havik, T., \& Heyne, D. (2019). Emerging school refusal: A school-based framework for identifying early signs and risk factors. Cognitive Behavioral Practice, 26, 46-62. https://doi.org/10.1016/j.cbpra.2018.03.005

Ishikawa, R. (2002). Futoukou to Chichioya no Yakuwari (School Refusal and The Role of The Father). Tokyo: Seikyusha. (in Japanese)

Kearney, C. A., \& Bensaheb, A. (2006). School absenteeism and school refusal behavior: A review and suggestions for school-based health professionals. Journal of School Health, 76, 3-7. https://doi.org/10.1111/j.1746-1561.2006.00060.x

Kearney, C. A., \& Graczyk, P. (2014). A response to intervention model to promote school attendance and decrease school absenteeism. Child Youth Care Forum, 43, 1-25. https://doi.org/10.1007/s10566-013-9222-1

Kearney, C.A., \& Bates, M. (2005). Addressing school refusal behavior: Suggestion for frontline professionals. Children and Schools, 27, 207-216. https://doi.org/10.1093/cs/27.4.207

Kearney, C.A., Gonzálvez, C., Graczyk, P.A., \& Fornander, M. (2019a). Reconciling contemporary approaches to school attendance and school absenteeism: Toward promotion and nimble response, global policy review and implementation, and future adaptability (Part 1). Frontiers in Psychology, 10: 2222. https://doi.org/10.3389/fpsyg.2019.02222

King, N. J., Tonge, B., Heyne, D., Prichard, M., Rollings, S., Yong, D., Myerson, N., \& Ollendick, T. H. (1998). Cognitive-behavioral treatment of school-refusing children: A controlled evaluation. Journal of American Academy of Child and Adolescent Psychiatry, 37, 395-403. https://doi.org/10.1097/00004583-199804000-00017

Maeda N., \& Heyne, D. (2019). Rapid return for school refusal: A school-based approach applied with Japanese adolescents. Frontiers in Psychology, 10, 2862. https://doi.org/ 10.3389/fpsyg.2019.02862

Maeda, N. (2016). School-based behavioural consultation for school-refusal behaviour. International Journal of Psychological Studies, 8, 40-52. https://doi.org/10.5539/ijps.v8n1p40.

Maeda, N. (2017). School refusal after the summer holiday: School-based behavioural approach for school refusal. Kyoiku to Igaku (Education and Medicine), 65, 812-820. (in Japanese)

Maeda, N., \& Hatada, S. (2019). The school attendance problem in Japanese compulsory education: The case of a public junior high school. European Journal of Education and Psychology, 12, 63-75. https://doi.org/10.30552/ejep.v12i1.241 
Maeda, N., Hatada, S., Sonoda, J., \& Takayama, I. (2012). School-based intensive exposure therapy for school refusal behavior. Clinical Case Studies, 11, 299-311. https://doi.org/ 10.1177/1534650112457456

Maeda,N., Takayama, I., \& Sonoda, J. (2012). A case study of a junior high school student who returned to classroom with behavioural psycho-education and active paternal intervention. Japanese Society of Psychosomatic Medicine, 52, 141-147. https://doi.org/10.15064/jjpm.52.2_141. (in Japanese)

Ministry of Education, Culture, Sports, Science, and Technology-Japan. (2003). Futoukou heno taiou ni tsuite (Approach to School Attendance Problem). Available online at: https://www.mext.go.jp/a_menu/shotou/futoukou/main.htm. (in Japanese)

Ministry of Education, Culture, Sports, Science, and Technology-Japan (MEXT) (2009). Futoukou no jidouseito heno shien ni tsuite (Regarding support for school-refusing students). Available online at: https://www.mext.go.jp/b_menu/shingi/chukyo/chukyo3/siryo/attach/1286947.htm. (in Japanese)

Ministry of Education, Culture, Sports, Science, and Technology-Japan. (2015). Gakkou ni okeru kyouikusoudan ni kansuru siryou (Materials on School-Based Educational Counseling). Tokyo. (in Japanese)

Ministry of Education, Culture, Sports, Science, and Technology-Japan. (2019). Jidouseito no mondaikoudou futoukoutou seitoshidoujou no shokadai ni kansuru chousa (Research on issues over teacher guidance toward student's misbehavior). Tokyo. (in Japanese)

Ministry of Education, Culture, Sports, Science, and Technology-Japan. (2007). Sukuuru kaunseraa ni tshuite (Regarding School Counselor). Available online at: https://www.mext.go.jp/b_menu/shingi/chousa/shotou/066/gaiyou/attach/1369846.htm. (in Japanese)

Ministry of Education, Culture, Sports, Science, and Technology-Japan. (2020). Sukuuru kaunseraatou katsuyoujigyou ni kansuru $Q \& A$ (Question and Answer about School Counselor Project), Tokyo. (in Japanese)

Okuyama, M., Okada, M., Kuribayashi, M., \& Kaneko, S. (1999). Factors responsible for the prolongation of school refusal. Psychiatry Clinical Neurosciences. 53, 461-469. https://doi.org/10.1046/j.1440-1819.1999.00585.x

Richardson, K. (2016). Family therapy for child and adolescent school refusal. Australian and New Zealand Journal of Family Therapy, 37, 528-546. https://doi.org/10.1002/anzf.1188.

Sewell, J. (2008). School refusal. Australian Family Physician, 37, 406-408.

Shinohara, K. (2008). Seitoshidou to hou (Student guidance and laws). In K. Shinohara (Ed.), Gakkou No Tame No Hougaku (Laws for School: Toward the Development of Independent and Cooperative School) (pp. 128-154). Kyoto: Minerubashobou. (in Japanese)

Sonoda, J., Hashimoto, K., Ishibashi, C., \& Kamohara, Y. (2008). Contemporary subjects to support of school non-attendance: From viewpoints of behavioral science. Journal of Kibi International University, Research Institute of Clinical Psychology, 5, 1-22. (in Japanese)

Takahashi, T., \& Yamada, T. (2008). Analyzing effect size indices single-case research data. Japanese Journal of Behavior Analysis, 22, 49-67. https://doi.org/10.24456/jjba.22.1_49. (in Japanese)

Terada, M. (2010). The treatment of non-attendance children 8: What we can do in our school now. Bulletin of Tokai Gakuin University, 4, 185-201. (in Japanese)

Terada, M. (2015). The treatment of non-attendance children 11: The framework of the treatment in school. Bulletin of Tokai Gakuin University, 9, 101-118. (in Japanese)

Thambirajah, M. S., Granduson, K. J., \& De-Hayes, L. (2008). Understanding School Refusal. A Handbook for Professionals in Education, Health and Social Care. London and Philadelphia: Jessica Kingsley.

Yagi, D. T. (2008). Current development in school counseling in Japan. Asian Journal of Counselling, 15, 141-155.

\section{Copyrights}

Copyright for this article is retained by the author(s), with first publication rights granted to the journal.

This is an open-access article distributed under the terms and conditions of the Creative Commons Attribution license which permits unrestricted use, distribution, and reproduction in any medium, provided the original work is properly cited. 